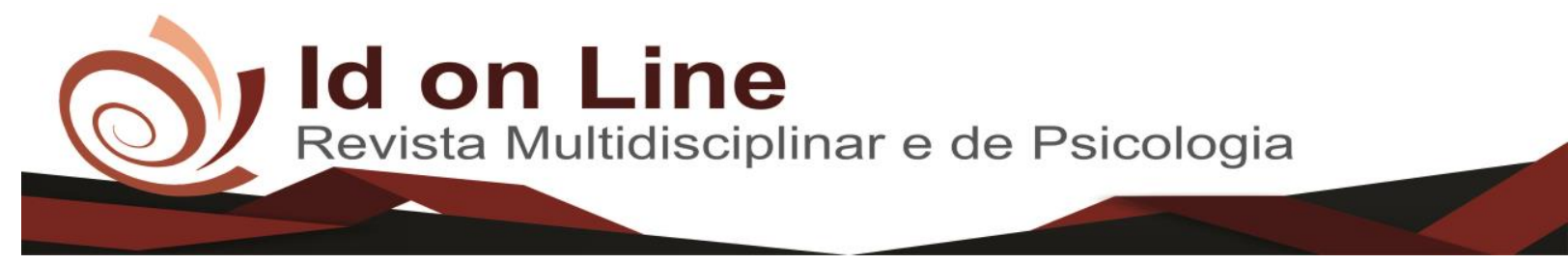

Artigo

\title{
Educação Infantil: Um estudo sobre a influência da oferta de vagas e a qualidade do ensino
}

\author{
Neila Carla Silva Rodrigues ${ }^{\text {; }}$ Josaias Santana dos Santos ${ }^{2}$;Raimundo Nonato Lima Filho ${ }^{3}$
}

\begin{abstract}
Resumo: Este estudo averiguou a correlação entre a oferta de vagas e a qualidade do Índice de Desenvolvimento da Educação Básica - IDEB. Existem, atualmente, no Brasil, políticas públicas que se destinam a expandir a oferta de vagas nas creches e pré-escolas, no entanto, esse fator não necessariamente interferirá na qualidade da educação, por essa razão, é importante a realização de estudos nesse sentido. Esta pesquisa foi caracterizada como documental, descritiva e quantitativa. Foi realizada a análise da correlação entre o IDEB e do número de matrículas na educação básica, referentes ao período de 2007 a 2015, das 100 maiores cidades brasileiras. Com os resultados encontrados, através da aplicação da Correlação de Pearson, destaca-se se que não há correlação entre a oferta de vagas, evidenciada a partir da quantidade de alunos matriculados na creche e pré-escola, e a qualidade do IDEB. Desse modo, demonstrou-se que o aumento ou redução na oferta de vagas não tem relação direta com a qualidade do ensino e aprendizagem, considerando-o isoladamente.
\end{abstract}

Palavras-Chave: políticas públicas, educação infantil, qualidade na educação, oferta de vagas.

\section{Early Childhood Education: A study on the influence of position offers and the quality of education}

\begin{abstract}
This study verified the correlation between the vacancy offer and the quality of Development of Basic Education Index (IDEB). Nowadays in Brazil, public policies are designed to expand the number of vacancies in kindergartens and pre-schools. However, this factor will not necessarily interfere with the quality of education. Therefore, performing studies related to this subject is important. This research was characterized as documentary, descriptive and quantitative. The analysis performed covered the correlation between IDEB and the number of enrollments in basic education, for the period from 2007 through 2015, of the 100 largest brazilian cities. With the results found through the application of Pearson's Correlation, the number of vacancies (evidenced by the number of students enrolled in kindergartens and pre-schools) and the quality of IDEB showed no correlation. Thus, neither increasing nor decreasing the number of vacancies is directly related to the quality of teaching and learning, which is considered isolated.
\end{abstract}

Keywords: public policies, childhood education, quality in education, number of vacancies.

\section{Introdução}

\footnotetext{
${ }^{1}$ Neila Carla Silva Rodrigues. Graduada em Ciências Contábeis pela Universidade do Estado da Bahia - UNEB, (2016). Pós-graduanda na Especialização em Gestão Pública pela Universidade Federal do Vale do São Francisco - UNIVASF (2018). Assistente em Administração na Universidade Federal do Recôncavo da Bahia -UFRB. E-mail: neilarodriguess2@ hotmail.com. Cel: (74)988268428. Autora correspondente. 2 Josaias Santana dos Santos. Mestre em Ciências Contábeis pela Fucape Bussines School - FUCAPE (2015). Graduação em Ciências Contábeis pela Faculdade de Ciências Aplicadas e Sociais de Petrolina - FACAPE (2004). Especializado em Gestão da Administração Pública pela Universidade Castelo Branco - UCB (2008). Contador da Universidade Federal do Vale do São Francisco - UNIVASF. É Professor Assistente do Quadro Permanente da FACAPE. E-mail: josaias.santana@univasf.edu.br.

${ }^{3}$ Raimindo Nonato Lima Filho. Doutor em Controladoria e Contabilidade pela Universidade de São Paulo - USP (2016). Doutor em Administração pela Universidade Federal da Bahia - UFBA (2013). Pós-Doutor pela Universidade Federal da Paraíba - UFPB (2014). É Professor da Autarquia Educacional do Vale do São Francisco (AEVSF). E-mail: rnlfilho@gmail.com.
} 
No Brasil, as ações do poder público são materializadas por meio de políticas públicas. De acordo com Rua (2012), políticas públicas podem ser definidas como um conjunto de decisões e ações referentes à destinação imperativa de recursos públicos. Essas políticas objetivam assegurar direitos pertencentes à sociedade, a determinados grupos ou a certos segmentos sociais, étnicos, culturais ou econômicos previstos na Constituição Federal de 1988. Por meio das políticas públicas, o governo decide o que fazer ou não fazer e como fazer, ou seja, decide em qual área, em quanto tempo e como irá investir os recursos públicos, observando o financeiramente possível e buscando oferecer ao menos o mínimo necessário à existência dos administrados.

Algumas políticas públicas provocam maior impacto e transformação, repercutindo por mais tempo na sociedade. Entre essas políticas, estão aquelas direcionadas à promoção da educação, sobretudo ao desenvolvimento da educação na primeira infância, que compreende o período que vai do nascimento até os cinco anos de idade. Segundo o Comitê Científico do Núcleo Ciência Pela Infância (2014), a educação está entre os fatores que provocam maior influência no nível de bem-estar das pessoas ao longo da vida. Para esse comitê, as crianças que têm um saudável desenvolvimento integral durante os primeiros anos de vida possuem mais facilidade de adquirir novos conhecimentos, como consequência, obterão bom desempenho escolar, realização profissional e melhores níveis socioeconômicos e de qualidade de vida.

Fujimoto (2016) pondera que a primeira infância é importante, pois é nela que as bases fundamentais do desenvolvimento humano, sejam físicas, sejam psicológicas, sociais e emocionais, são estruturadas. Para a referida autora, não há muitas dúvidas de que investir no desenvolvimento da criança em seus primeiros anos de vida propicia um maior retorno à sociedade do que investir em outros projetos.

A Carta Magna brasileira assevera que as crianças e os adolescentes têm absoluta prioridade no que tange ao direito à vida, à saúde, à alimentação, à educação, ao lazer, à profissionalização, à cultura, à dignidade, ao respeito, à liberdade e à convivência familiar e comunitária. Esses são direitos que se posicionam além da conveniência e oportunidade, não podem ser condicionados, negligenciados ou protelados. A criança não pode renunciá-los; são inescusáveis para o Estado, para a família e para a sociedade, aos quais compete assegurar-lhe, ou seja, não podem deles dispor.

Em que pese existir um arcabouço legal que defende e protege os direitos das crianças neste país, ainda há deficiência na formulação e implementação de políticas públicas, 
principalmente no que se refere à educação. O Plano Nacional de Educação - PNE, lei ordinária com vigência decenal, prevista no artigo 214 da Carta Constitucional Brasileira, estabelece diretrizes, metas e estratégias de concretização no campo educacional. Já foram instituídos dois PNEs, sendo que o segundo ainda está vigente, as metas que neles foram estabelecidas em relação à ampliação da oferta da educação infantil não foram totalmente cumpridas pelo Estado.

A demanda por vagas é maior do que a oferta, além disso, não é possível garantir que o ensino ofertado na primeira infância está sendo de qualidade em todo o Estado. Em virtude disso, este estudo busca responder ao seguinte problema de pesquisa: há correlação entre a oferta de vagas e a qualidade do Índice de Desenvolvimento da Educação Básica - IDEB?

O objetivo deste trabalho é verificar se existe uma correlação entre a oferta de vagas, evidenciada a partir da quantidade de alunos matriculados na creche e pré-escola, e a qualidade do IDEB, buscando aferir se a relação entre a oferta de educação infantil gera maior qualidade nos indicadores de avaliação.

Leal (2016) desenvolveu um estudo buscando entender a díade quantidade e qualidade do ensino superior ofertado por meio do Programa Universidade para Todos - Prouni e do Fundo de Financiamento Estudantil - FIES, a autora concluiu que apesar de esses programas abrirem um leque de oportunidades para a sociedade, na medida em que expandem a oferta de cursos de nível superior, não atendem os padrões mínimos de qualidade para a capacitação profissional do indivíduo.

Nessa mesma linha de correlação entre quantidade e qualidade, foi publicada pelo jornal A Folha de São Paulo uma reportagem, a qual noticiava que a produção científica neste país, entre 2001 e 2011, cresceu, entretanto o índice de qualidade caiu (Righetti, 2013). Isso denota que houve uma relação inversamente proporcional entre a quantidade da produção científica e a sua qualidade. Assim, observa-se que qualidade nem sempre está diretamente relacionada à quantidade. Diante disso, faz-se importante uma pesquisa nesse sentido, a fim de verificar se existe uma correlação entre a quantidade de vagas ofertadas e a qualidade da educação infantil.

Além desta, o artigo possui mais quatro seções. Na seção 2, apresenta-se a revisão de literatura acerca do tema abordado, acentuando os trabalhos mais recentes. Na seção 3, são apresentados os procedimentos metodológicos da pesquisa. Em sequência, vem seção 4, onde são expostos os resultados e, por fim, estão as considerações finais. 


\section{O papel do Estado na educação infantil}

A educação é um direito social previsto na Constituição Federal de 1988, é dever do Estado e da família e é uma prioridade absoluta para as crianças e adolescentes. A partir desse dispositivo legal, no qual há uma seção reservada apenas para as garantias relacionadas à educação, esse direito começou a ganhar destaque. A Lei de Diretrizes e Bases - LDB e o Plano Nacional de Educação - PNE são outros institutos legais que balizam e definem diretrizes e planos de ação para a educação, baseados nas disposições e princípios constitucionais.

A Emenda Constitucional n ${ }^{\circ}$. 14, de 12 de setembro de 1996 altera a Carta de 1988, determinando que o direito à educação abrange não somente a garantia de acesso e permanência ao ensino, mas também a garantia de um ensino de qualidade, de forma que os governantes podem ser responsabilizados juridicamente pela sua oferta irregular ou pelo seu não oferecimento.

A partir da promulgação dessa Emenda, foi criado o Fundo de Manutenção e Desenvolvimento da Educação Básica e Valorização do Magistério, assim, essa etapa educacional foi impulsionada, uma vez que a creche e a pré-escola passaram a ter seu financiamento previsto em lei.

A Constituição Federal de 1988 ainda prevê que o Estado tem o dever de efetivar a educação, garantindo a educação infantil em creches e pré-escolas às crianças de até cinco anos de idade. Essa garantia, consoante os dispositivos constitucionais e a LDB, é de responsabilidade dos municípios, mas para sua efetivação faz-se necessário que haja uma ação conjunta entre os governos federal, estadual, distrital e municipal.

\section{Plano Nacional de Educação}

Em 1996, a LDB, em consonância com a Carta Constitucional, determinou a criação do PNE, que é de responsabilidade da União com a colaboração dos Estados, Municípios e Distrito Federal (Brasil, 1996). O PNE I foi instituído pela Lei $n^{\circ}$. 10.172/2001 e representou um documento de grande importância para a educação brasileira, uma vez que sistematizou um conjunto de diretrizes, metas e estratégias para todos os níveis e modalidades do ensino (Azevedo, 2014). 
O primeiro PNE, que vigorou no período de 2001-2010, previa, na Meta 1, a ampliação da oferta da educação infantil, de maneira a atender pelo menos $50 \%$ das crianças de zero a três anos e $80 \%$ das crianças de quatro a cinco anos, até o final da década; já o segundo PNE, com vigência de 2014-2024, determina, na Meta 1, a ampliação da educação infantil para atender, no mínimo, $50 \%$ das crianças de até três anos de idade, até o final da vigência, e estabelece a universalização da educação infantil na pré-escola para crianças de quatro a cinco anos, até 2016.

Ao final da vigência do primeiro PNE, em média, 80,23\% das crianças de quatro a cinco anos estavam sendo beneficiadas com a educação infantil, isso denota que o Brasil atingiu a meta prevista para essa faixa, entretanto as desigualdades regionais existentes não permitem afirmar que essa meta foi efetivamente cumprida em todos os pontos do país. Quanto à etapa de zero a três anos, o país descumpriu a meta do PNE anterior, que fora postergada para o final do plano vigente.

Pelo exposto, percebe-se que há um esforço no sentido de ampliar a oferta de vagas com o objetivo de atender o maior número de crianças possível, entretanto ainda existem muitos desafios a serem superados para que as metas para alcançar tal ação sejam cumpridas.

\section{Qualidade da Educação Infantil}

Qualidade é um termo abrangente que envolve diversos aspectos para chegar a uma definição que, na maioria das vezes, não é consensual. Corrêa (2003) pondera que esse termo não é traduzido em conceito único, universal e absoluto, cabendo, portanto, aos múltiplos setores sociais tomá-lo de maneira diversa um dos outros.

A qualidade pode estar relacionada a fatores como infraestrutura dos ambientes escolares, qualificação, reconhecimento e remuneração dos educadores, características e condições sociais e econômicas dos familiares, características individuais das crianças e condições socioeconômicas regionais. Além disso, esse indicador também pode ter relação com a oferta de vagas pelo poder público.

Sylva et al. (2010), em um estudo realizado na Inglaterra, encontrou alguns resultados que servem de subsídios para a caracterização da qualidade na educação infantil. Dentre os principais resultados da pesquisa, pode-se destacar que crianças pertencentes à classe baixa 
podem ser beneficiadas com uma pré-educação de qualidade, principalmente se participarem de centros dos quais fazem parte crianças de diversas origens sociais; a qualidade das préescolas tem relação direta com melhores resultados no desenvolvimento intelectual, social e comportamental das crianças; e centros que dispõem de profissionais mais qualificados e com quantidade proporcional ao número de alunos possuem maior qualidade.

Nessa mesma linha, Campos et al. (2011) fazem um estudo sobre a qualidade da educação infantil em seis capitais brasileiras, após interpretação dos dados, os autores puderam afirmar que as creches que apresentam melhores índices de qualidade possuem melhor infraestrutura, os professores são mais jovens e desenvolvem diariamente várias atividades com as crianças, contam com um bom número de equipamentos, entre outras características. Ainda de acordo com esses autores, as pré-escolas com melhores medidas de qualidade possuem professores que realizam pós-graduação, seus diretores desenvolvem cursos direcionados ao quadro de pessoal da sua própria unidade, além de terem ingressado por meio de processos seletivos ou eleições. De maneira geral, eles observaram que essas instituições apresentam níveis insatisfatórios de qualidade tanto para creches, quanto para pré-escolas e que as instituições avaliadas negligenciam muitos aspectos primordiais voltados para as crianças nessa faixa etária.

Pelo exposto, verifica-se que outros estudos correlacionaram a questão da qualidade com vários fatores que podem ser considerados importantes para o desenvolvimento da educação infantil com qualidade. Em termos quantitativos, houve um avanço no atendimento das crianças na pré-escola no Brasil, porém a melhoria da qualidade da educação deste país, bem como a valorização e formação dos profissionais se encontram sendo frequentemente debatidos (MIRANDA; ALVES; CESTARO, 2015). Miranda et al. (2015) afirmam que a formação dos profissionais da área da educação compromete a qualidade do atendimento disponibilizado à infância brasileira. 


\section{Procedimentos Metodológicos}

\section{Caracterização da pesquisa e obtenção dos dados}

Com a finalidade de alcançar respostas para o problema do estudo, foram delineados os procedimentos metodológicos. Inicialmente procedeu-se à coleta dos dados, que foram obtidos a partir dos seguintes sites oficiais: www.inep.gov.br - Instituto Nacional de Estudos e Pesquisas Educacionais Anísio Teixeira - INEP, www.observatoriodopne.org.br - Observatório do Plano Nacional de Educação, www.ibge.gov.br - Instituto Brasileiro de Geografia Estatística - IBGE e www.fnde.gov.br - Fundo Nacional de Desenvolvimento da Educação - FNDE.

Foi feita uma análise do IDEB das 100 maiores cidades deste país, estas foram definidas conforme estimativas da população residente no Brasil e unidades da federação, feitas pelo IBGE, com data de referência em $1^{\circ}$ de julho de 2017, comparando-os com a oferta de vagas, evidenciada pelo número de matrículas, em escolas e creches na primeira infância. Para tanto, foi usada a Correlação de Pearson que "mensura a direção e o grau da relação linear entre duas variáveis quantitativas" (MOORE, 2007, pg 100/101).

Em face das características, depreende-se que, quanto aos objetivos da pesquisa, este é um estudo do tipo descritivo, quanto aos procedimentos ele é classificado como documental e em relação à abordagem do problema caracteriza-se como quantitativo. De acordo com Raupp e Beuren (2013), uma pesquisa se enquadra como descritiva pelo fato de identificar, descrever, relatar, e comparar aspectos ou comportamentos de determinada população analisada. Portanto, é possível considerar uma pesquisa como documental quando, entre outros fatores, ela pode organizar informações que estão dispersas, atribuindo-lhes uma nova importância como fonte de consulta. A abordagem será quantitativa, já que serão empregados instrumentos e técnicas estatísticas.

\section{Plano de análise dos dados}

Para coletar, organizar, analisar- e interpretar os dados, inicialmente foram identificadas as 100 maiores cidades do Brasil em população. Na tabela abaixo, encontram-se listadas por ordem decrescente da população estimada: 
Quadro 1 - 100 maiores municípios do Brasil, 2017

\begin{tabular}{|c|c|c|c|c|c|}
\hline UF & Município & População & UF & Município & População \\
\hline SP & São Paulo & 12.106 .920 & RJ & São João de Meriti & 460.461 \\
\hline $\mathrm{RJ}$ & Rio de Janeiro & 6.520 .266 & SP & São José do Rio Preto & 450.657 \\
\hline DF & Brasília & 3.039 .444 & SP & Santos & 434.742 \\
\hline $\mathrm{BA}$ & Salvador & 2.953 .986 & SP & Mogi das Cruzes & 433.901 \\
\hline $\mathrm{CE}$ & Fortaleza & 2.627 .482 & MG & Betim & 427.146 \\
\hline MG & Belo Horizonte & 2.523 .794 & SP & Diadema & 417.869 \\
\hline $\mathrm{AM}$ & Manaus & 2.130 .264 & PB & Campina Grande & 410.332 \\
\hline PR & Curitiba & 1.908 .359 & SP & Jundiaí & 409.497 \\
\hline $\mathrm{PE}$ & Recife & 1.633 .697 & PR & Maringá & 406.693 \\
\hline $\mathrm{RS}$ & Porto Alegre & 1.484 .941 & MG & Montes Claros & 402.027 \\
\hline GO & Goiânia & 1.466 .105 & SP & Piracicaba & 397.322 \\
\hline $\mathrm{PA}$ & Belém & 1.452 .275 & SP & Carapicuíba & 396.587 \\
\hline SP & Guarulhos & 1.349 .113 & PE & Olinda & 390.771 \\
\hline SP & Campinas & 1.182 .429 & ES & Cariacica & 387.368 \\
\hline MA & São Luís & 1.091 .868 & $\mathrm{AC}$ & Rio Branco & 383.443 \\
\hline $\mathrm{RJ}$ & São Gonçalo & 1.049 .826 & GO & Anápolis & 375.142 \\
\hline $\mathrm{AL}$ & Maceió & 1.029 .129 & SP & Bauru & 371.690 \\
\hline $\mathrm{RJ}$ & Duque de Caxias & 890.997 & ES & Vitória & 363.140 \\
\hline $\mathrm{RN}$ & Natal & 885.180 & $\mathrm{CE}$ & Caucaia & 362.223 \\
\hline MS & Campo Grande & 874.210 & SP & Itaquaquecetuba & 360.657 \\
\hline PI & Teresina & 850.198 & SP & São Vicente & 360.380 \\
\hline SP & São Bernardo do Campo & 827.437 & $\mathrm{PE}$ & Caruaru & 356.128 \\
\hline PB & João Pessoa & 811.598 & BA & Vitória da Conquista & 348.718 \\
\hline $\mathrm{RJ}$ & Nova Iguaçu & 798.647 & SC & Blumenau & 348.513 \\
\hline SP & Santo André & 715.231 & SP & Franca & 347.237 \\
\hline SP & São José dos Campos & 703.219 & RS & Pelotas & 344.385 \\
\hline SP & Osasco & 697.886 & PR & Ponta Grossa & 344.332 \\
\hline $\mathrm{PE}$ & Jaboatão dos Guararapes & 695.956 & RS & Canoas & 343.853 \\
\hline SP & Ribeirão Preto & 682.302 & $\mathrm{PE}$ & Petrolina & 343.219 \\
\hline $\mathrm{MG}$ & Uberlândia & 676.613 & RR & Boa Vista & 332.020 \\
\hline SP & Sorocaba & 659.871 & MG & Ribeirão das Neves & 328.871 \\
\hline $\mathrm{MG}$ & Contagem & 658.580 & $\mathrm{PE}$ & Paulista & 328.353 \\
\hline SE & Aracaju & 650.106 & MG & Uberaba & 328.272 \\
\hline $\mathrm{BA}$ & Feira de Santana & 627.477 & PR & Cascavel & 319.608 \\
\hline MT & Cuiabá & 590.118 & SP & Guarujá & 315.563 \\
\hline $\mathrm{SC}$ & Joinville & 577.077 & SP & Praia Grande & 310.024 \\
\hline $\mathrm{MG}$ & Juiz de Fora & 563.769 & SP & Taubaté & 307.953 \\
\hline PR & Londrina & 558.439 & PR & São José dos Pinhais & 307.530 \\
\hline $\mathrm{GO}$ & Aparecida de Goiânia & 542.090 & SP & Limeira & 300.911 \\
\hline $\mathrm{RO}$ & Porto Velho & 519.436 & RJ & Petrópolis & 298.235 \\
\hline $\mathrm{PA}$ & Ananindeua & 516.057 & $\mathrm{BA}$ & Camaçari & 296.893 \\
\hline ES & Serra & 502.618 & $\mathrm{PA}$ & Santarém & 296.302 \\
\hline
\end{tabular}




\begin{tabular}{|c|l|r|r|l|l|} 
& Сопtіпиа... & & & & \\
\hline RJ & Niterói & 499.028 & RN & Mossoró & 295.619 \\
\hline RJ & Belford Roxo & 495.783 & SP & Suzano & 290.769 \\
\hline RJ & Campos dos Goytacazes & 490.288 & TO & Palmas & 286.787 \\
\hline ES & Vila Velha & 486.388 & MG & Governador Valadares & 280.901 \\
\hline SC & Florianópolis & 485.838 & SP & Taboão da Serra & 279.634 \\
\hline RS & Caxias do Sul & 483.377 & RS & Santa Maria & 278.445 \\
\hline AP & Macapá & 474.706 & RS & Gravatá & 275.146 \\
\hline SP & Mauá & 462.005 & MT & Várzea Grande & 274.013 \\
\hline
\end{tabular}

Fonte: Diretoria de Pesquisas - DPE - Coordenação de População e Indicadores Sociais - COPIS, 2017

Identificadas as cidades, percebeu-se que elas estão localizadas nas diferentes regiões do país e têm desenvolvimento socioeconômico desigual, o que faz inferir que os índices de qualidade da educação serão diferentes, visto que cada uma possui características peculiares. Após isso, foi levantado o IDEB dessas cidades. Esse índice é calculado a cada dois anos e sua primeira divulgação ocorreu em 2005. Assim, foram considerados os IDEBs do período que compreende 2005 a 2015. Posteriormente, houve a coleta do número de matriculas na creche e pré-escola, nos respectivos municípios da amostra, dos mesmos anos em que houve cálculo do IDEB, exceto 2005, pois não estava disponível no site do FNDE nem foram encontrados em sites correlatos.

Tendo sido coletados todos os dados: IDEB e número de matrículas, e considerando o período em que tinham dados disponíveis de ambas as variáveis, 2007 a 2015, calculou-se a variação percentual bienal ocorrida em cada variável. Por fim, fez-se a correlação entre a variação percentual bienal do IDEB e do número de matrículas, a fim de verificar se o aumento ou diminuição de um tem relação direta ou inversa no outro, ou se não há nenhuma interferência.

Essa correlação foi realizada por meio do método Pearson, que busca avaliar se há relação linear entre duas variáveis contínuas. Sendo que uma relação é linear quando a alteração em uma variável é associada a uma modificação proporcional na outra variável. 


\section{Teste de normalidade}

Para testar a normalidade do conjunto de dados, foi proposto o teste KolmogorovSmirnov, aperfeiçoado por Lilliefor, uma vez que as amostras têm características diferentes. Kolmogorov-Smirnov é um teste capaz de verificar se existe alguma relação entre a amostra e a distribuição de probabilidade especificada (BARBETTA; REIS; BORNIA, 2010). Assim, com esse teste, avaliou-se a hipótese que afirma que as variáveis possuem distribuição normal. Foi considerado o nível de significância de 5\%, frequentemente adotado nos testes estatísticos, conforme exposto abaixo:

$H_{0}<5 \%$ : rejeita-se a hipótese nula;

$H_{0}>5 \%$ : aceita-se a hipótese nula.

O quadro 2 demonstra o resultado obtido com a aplicação desse teste:

Quadro 2 - Teste de Normalidade

\begin{tabular}{|c|c|c|c|c|c|c|}
\hline & \multicolumn{3}{|c|}{ Kolmogorov-Smirnov $^{\mathrm{a}}$} & \multicolumn{3}{c|}{ Shapiro-Wilk } \\
\cline { 2 - 7 } & Statistic & $\mathrm{df}$ & Sig. & Statistic & df & Sig. \\
\hline IDEB2007_2009 &, 118 & 101 &, 001 &, 902 & 101 &, 000 \\
\hline IDEB2009_2011 &, 102 & 101 &, 012 &, 972 & 101 &, 029 \\
\hline IDEB2011_2013 &, 093 & 101 &, 032 &, 987 & 101 &, 400 \\
\hline IDEB2013_2015 &, 118 & 101 &, 001 &, 872 & 101 &, 000 \\
\hline MAT2007_2009 &, 170 & 101 &, 000 &, 817 & 101 &, 000 \\
\hline MAT2009_2011 &, 434 & 101 &, 000 &, 197 & 101 &, 000 \\
\hline MAT2011_2013 &, 140 & 101 &, 000 &, 873 & 101 &, 000 \\
\hline MAT2013_2015 &, 179 & 101 &, 000 &, 880 & 101 &, 000 \\
\hline
\end{tabular}

Fonte: elaboração própria, 2018

a. Lilliefors Significance Correction

O resultado do teste, na maioria dos biênios, foi inferior ao nível de significância de 5\%, o que fez com que a hipótese nula da normalidade de distribuição dos dados fosse rejeitada. Como os dados da pesquisa não estão voltados para a normalidade, aplicou-se o método de correlação de Pearson. Esse método apresenta coeficientes que podem variar de -1 a 1 . Sendo que o sinal indica se há uma associação positiva ou negativa entre as variáveis e o valor mostra 
o grau de relação que há entre elas, já uma relação de valor zero mostra que não há relação linear entre as variáveis (FIGUEIREDO FILHO; SILVA JÚNIOR, 2009). Será positivo quando uma variável aumenta e a (s) outra (s) também aumentam e chegará a exatamente 1 se esse aumento for em quantidade consistente; em contrapartida, será negativo quando uma variável aumenta e a outra diminui, se chegar a exatamente -1, há uma correlação decrescente perfeita.

\section{Análise e Discussão dos Resultados}

As cidades que fazem parte da amostra estão localizadas nas diferentes regiões do país, a maioria são as capitais dos estados. Alguns estados foram representados por mais de uma cidade, o mais contemplado foi o de São Paulo, uma vez que é o estado que possui mais cidades populosas do país. O que se observou, a partir das variações percentuais tanto das matrículas, quanto do IDEB, é que não teve um período em que houve só redução ou só aumento, ora o número de matrícula de determinada cidade aumentava, ora reduzia. Isso pode ser evidenciado a partir da tabela abaixo, a qual apresenta a média da variação percentual do IDEB e das matrículas nas cidades e nos anos considerados:

Tabela 1 - Média da variação percentual do IDEB e das matrículas

\begin{tabular}{r|r|r|r|r|r|r|r}
\hline \multicolumn{4}{|c|}{ IDEB } & \multicolumn{4}{c}{ MATRÍCULAS } \\
\hline $2007 / 2009$ & $2009 / 2011$ & $2011 / 2013$ & $2013 / 2015$ & $2007 / 2009$ & $2009 / 2011$ & $2011 / 2013$ & $2013 / 2015$ \\
\hline $10,6 \%$ & $5,5 \%$ & $3,55 \%$ & $7,8 \%$ & $67,1 \%$ & $43,1 \%$ & $6,1 \%$ & $10,8 \%$ \\
\hline
\end{tabular}

Fonte: elaboração própria, 2018

Nota-se que entre o biênio 2007/2009 houve uma média de 10,6\% na variação do IDEB, essa média caiu quase metade no biênio seguinte e continuou a cair posteriormente, só no último biênio é que ela voltou a subir. Já as matrículas apresentaram uma média alta nos dois primeiros biênios e nos dois últimos a média reduziu bastante. Assim, denota-se que os dados das variáveis não apresentaram uma tendência padrão de redução ou de aumento.

Considerando o que foi exposto acima e levando em conta o teste de normalidade aplicado, foi pertinente verificar a associação que há entre a variação percentual das variáveis em questão pelo método de Pearson. Tendo em vista os dados da amostra, para definir se há ou não correlação entre a variação do IDEB e da matrícula é necessário fazer uma análise conjunta 
com o nível de significância adotado, uma vez que estatisticamente não há como aceitar a hipótese testada se este for superior ao limite tolerável (5\%), pois se assim o for, não haverá um resultado com grau de confiança aceitável, isto é, igual ou superior a 95\%. Com isso, abaixo são apresentados os resultados da correlação realizada:

Quadro 3 - Resultado da correlação entre o IDEB e as matrículas

\begin{tabular}{|c|c|c|c|}
\hline & & IDEB 2007_2009 & MAT 2007_2009 \\
\hline \multirow{3}{*}{ IDEB 2007_2009 } & Pearson Correlation & 1 & $-0,01$ \\
\hline & Sig. (2-tailed) & & 0,92 \\
\hline & $\mathrm{N}$ & 101 & 101 \\
\hline & & IDEB 2009_2011 & MAT 2009_2011 \\
\hline \multirow{3}{*}{ IDEB 2009_2011 } & Pearson Correlation & 1 & $-0,032$ \\
\hline & Sig. (2-tailed) & & 0,749 \\
\hline & $\mathrm{N}$ & 101 & 101 \\
\hline & & IDEB 2011 _ 2013 & MAT 2011_2013 \\
\hline \multirow{3}{*}{ IDEB 2011_2013 } & Pearson Correlation & 1 & $-0,013$ \\
\hline & Sig. (2-tailed) & & 0,896 \\
\hline & $\mathrm{N}$ & 101 & 101 \\
\hline & & IDEB 2013_2015 & MAT 2013_2015 \\
\hline \multirow{3}{*}{ IDEB 2013_2015 } & Pearson Correlation & 1 & $-0,17$ \\
\hline & Sig. (2-tailed) & & 0,089 \\
\hline & $\mathrm{N}$ & 101 & 101 \\
\hline
\end{tabular}

Fonte: elaboração própria, 2018

Iniciando a análise pelo primeiro biênio (2007/2009), vê-se que o resultado da correlação entre as duas variáveis foi de $-0,01$, o que, a princípio, demonstra uma correlação inversa, ou seja, à medida que a oferta de matrículas aumenta, o IDEB diminui, mas só é possível chegar a essa conclusão se for feita uma análise isolada da correlação, sem considerar o nível de significância. Fazendo uma apreciação considerando os dois prismas, denota-se que nesse biênio não houve associação entre o IDEB e a oferta de vagas na educação básica, uma vez que o grau de significância foi alto, chegando a 92\%, enquanto o nível de confiança ficou limitado a 8\%, rejeitando-se a hipótese nula de correlação entre as duas variáveis.

Em relação ao resultado do biênio 2009/2011, percebeu-se que houve um grau de confiança de apenas $25 \%$, isso sugere que, embora o resultado da correlação tenha indicado 
uma interferência negativa de uma variável na outra (-0,032), não é possível aceitar a hipótese nula. Dessa forma, comprovou-se que, nesse biênio também não houve associação entre os dois eventos.

O resultado da correlação da variação percentual no biênio 2011/2013 aponta para uma associação inversa, pois, como os anteriores, também foi negativo, porém o grau de incerteza foi bastante elevado (89\%), por essa razão rejeita-se a hipótese nula, corroborando que não há nenhuma relação entre as variáveis.

Analisando o último biênio considerado (2013/2015), a correlação de Pearson entre a variação percentual das variáveis resultou em um coeficiente de - 0,17 , entretanto, mais uma vez apresentou um nível de confiança baixo, por essa razão foi rejeitada a hipótese nula.

Pelo exposto, é possível observar que os fenômenos analisados não possuem uma correlação, quer seja positiva (que ocorreria caso a oferta aumentasse e o IDEB apresentasse um aumento proporcional, ou vice-versa), quer seja negativa (evidenciada pela redução de uma variável provocando redução proporcional na outra).

Assim, e respondendo a indagação que é objeto dessa pesquisa, comprovou-se que não há uma correlação entre a oferta de vagas, evidenciada a partir da quantidade de alunos matriculados na creche e pré-escola, e a qualidade do IDEB, o que significa que não importa o quanto a oferta de vagas na educação infantil aumenta ou diminui no decorrer dos anos, pois isso, por si só, não gera maior qualidade nos indicadores de avaliação da educação.

Como já fora exposto, o Estado instituiu o PNE, e, entre as metas que nele foram estabelecidas, existe uma que é direcionada às crianças que estão na educação básica, que se resume basicamente à universalização da pré-escola para as crianças de 4 e 5 anos e a atender pelo menos $50 \%$ das crianças de 0 a 3 anos. Há, portanto, um empenho no sentido de expandir a oferta de vagas objetivando atender o maior número de crianças possível, entretanto isso não pode ser considerado uma política pública que influenciará diretamente na qualidade da educação dessas crianças, não se considerada de forma isolada.

Nesse sentido, para proporcionar uma educação de qualidade para as crianças da creche e da pré-escola é importante que o Estado não se preocupe apenas com a oferta de vagas, mas que também implemente outras políticas públicas que possam influenciar mais no melhor aprendizado dos alunos e levar em consideração também fatores como a estrutura do ambiente em quem ocorrem as aulas, as características socioeconômicas dos alunos e de suas famílias, a forma como o ensino é repassado pelos professores e a qualificação que é dada a estes. 


\section{Considerações Finais}

A qualidade na educação infantil e até mesmo na educação de outras faixas etárias é um assunto que tem sido muito debatido e que tem tido destaque na área da pesquisa. Existem estudos que vão desde a problematização das inúmeras significações e conceitos relativos à qualidade da educação (como o que fora realizado por Dourado e Oliveira, 2009), até estudos como este que visa a aferir a interferência que determinada variável tem na qualidade da educação.

Esse estudo buscou averiguar se há correlação entre a oferta de vagas e a qualidade do IDEB. Para tanto, foram analisados o IDEB e a oferta de matrículas das 100 maiores cidades do Brasil, entre as quais estavam a maioria das capitais e muitas cidades do estado de São Paulo. Foi considerado o período que compreende 2007 a 2015, pois foi o interstício em que havia dados disponíveis das duas variáveis analisadas.

A análise dos dados foi feita considerando cada biênio em que havia publicação do IDEB, visto que esse índice não é aferido anualmente. Coletou-se o número de matrículas dos mesmos anos em que havia dados do IDEB. Como foi exposto no capítulo de Análise de discussão dos resultados, as cidades apresentaram uma variação percentual no IDEB e no número de matrícula que não seguiu uma linearidade, não foi crescente nem decrescente durante todo o período, ora o número de matrículas aumentava, ora diminuía, o mesmo ocorreu com o IDEB.

Com os resultados da correlação de Pearson, a hipótese nula que afirmava que havia correlação entre o IDEB e a oferta de vagas para crianças da creche e pré-escola foi rejeitada. Em que pese os coeficientes resultantes da correlação, em todos os biênios analisados, tenha demonstrado que houve uma correlação inversa entre as variáveis, não foi possível corroborar a hipótese nula, uma vez que o grau de incerteza do resultado foi bastante elevado.

Dessa forma, não foi possível afirmar que se o Estado aumentar a oferta de vagas haverá mais qualidade na educação básica. Esse fator não provoca essa melhoria se considerado separadamente de outros. Assim, há necessidade de uma análise conjunta do aumento da oferta de vagas com outros fatores que podem ter interferência no nível de qualidade da educação básica, a exemplo do Índice de Desenvolvimento Humano - IDH, o qual mede a evolução das pessoas considerando a renda, a educação e a saúde, a fim de verificar se a variável em análise, 
juntamente com outras tem correlação com uma melhora ou piora no IDEB. Essa pode ser uma problemática para futuras pesquisas relacionadas a esse assunto.

Os resultados da pesquisa trouxeram contribuições para a área da gestão pública, em especial para as políticas públicas, já que essas são definidas com base em diversos fatores, entre eles estão estudos prévios nas áreas em que serão aplicadas para que seja definida a melhor forma de efetivá-las. Assim, com um estudo que demonstra que expandir a oferta de vagas não implica diretamente melhoria no IDEB, pode ajudar aos atores que discutem e definem as políticas públicas a melhor direcioná-las.

\section{Referências}

AZEVEDO, J. M. L. Plano Nacional de Educação e planejamento: A questão da qualidade da educação básica. Revista Retratos da Escola. v. 8, n. 15, p. 265-280, jul./dez. 2014. Disponível em: <http://retratosdaescola.emnuvens.com.br/rde/article/view/441>. Acesso em: 06 de setembro de 2017.

BRASIL. Constituição Federal, de 05 de outubro de 1988, Brasília, DF: 1988. Disponível em: $<$ http://www.planalto.gov.br/ccivil_03/constituicao/constituicao .htm>. Acesso em: 02 de setembro de 2017.

Emenda Constitucional $\mathbf{n}^{\mathbf{0}}$ 14, de 12 de setembro de 1996, Brasília, DF: 1988. Disponível em: < http://www.planalto.gov.br/ccivil_03/constituicao/emendas/emc/ emc14.htm>. Acesso em: 04 de setembro de 2017.

. Lei n. 9.394, de 20 de dezembro de 1996, Brasília, DF: 1996. Estabelece as diretrizes e bases da educação nacional. Disponível em: <http://www.planalto.gov.br/ccivil_03/leis/L9394.htm>. Acesso em: 06 de setembro de 2017.

Comitê Científico do Núcleo Ciência Pela Infância (2014). Estudo nº 1: O Impacto do Desenvolvimento na Primeira Infância sobre a Aprendizagem. Disponível em: $<$ http://www.fmcsv.org.br/pt-br/acervo-digital/Paginas/O-impacto-nodesenvolvimento-daprimeira-inf\%C3\%A2ncia-sobre-a-aprendizagem.aspx>. Acesso em: 09 de setembro de 2017.

CAMPOS, M. M. et al. A qualidade da educação infantil: um estudo em seis capitais brasileiras. Revista Cadernos de Pesquisa. Disponível em: < http://publicacoes.fcc.org. br/ojs/index.php/cp/article/view/116>. Acesso em: 16 de setembro de 2017.

CORRÊA, B. C. Considerações sobre a qualidade na educação infantil. Revista Cadernos de Pesquisa. Disponível em: <http://publicacoes.fcc.org.br/ojs/index.php/cp/article/view/517>. Acesso em: 16 de setembro de 2017. 
DOURADO, L. F.; OLIVEIRA, J. P. Qualidade da educação: perspectivas e desafios. Cad. Cedes, Campinas. vol. 29, n. 78, p. 201-215, maio/ago. 2009. Disponível em: <http://www.cedes.unicamp.br>. Acesso em: 01 de maio de 2018.

FIGUEIREDO FILHO, D.B.; SILVA JÚNIOR, J.A. Desvendando os mistérios do coeficiente de correlação de Pearson (r). Revista Política Hoje. v. 18, n. 1, p. 115-46. Disponível em: <http://www.ufpe.br/politicahoje/index.php/politica/article/view/6/6>. Acesso em: 01 de maio de 2018.

FUNDO NACIONAL DE DESENVOLVIMENTO DA EDUCAÇÃO. Ministério da Educação. Matrículas, coeficientes de distribuição de recursos e receita anual prevista por Estado e Município. Disponível em: <http://www.fnde.gov.br/financiamento/fundeb/areapara-gestores/dados-estatisticos>. Acesso em: 09 de fevereiro de 2018.

FUJIMOTO, Gaby. Cenário Mundial das Políticas de Primeira Infância. Avanços no Marco Legal da Primeira Infância. p. 24-59. Brasília, 2016. Disponível em: <http://www2.camara.leg.br/a-camara/estruturaadm/altosestudos/pdf/obra-avancos-do-marco legal -da-primeira-infancia>. Acesso em: 29 de agosto de 2017.

INSTITUTO BRASILEIRO DE GEOGRAFIA E ESTATÍSTICA. Diretoria de Pesquisas DPE. Coordenação de População e Indicadores Sociais - COPIS, 2017. Estimativas populacionais para os municípios e para as Unidades da Federação brasileiros em 01.07.2017. Disponível em: <https://ww2.ibge.gov.br/home/estatistica/populacao/estimativa2017/ estimativa_dou.shtm>. Acesso em: 07 de fevereiro de 2018.

INSTITUTO NACIONAL DE ESTUDOS E PESQUISAS EDUCACIONAIS ANÍSIO TEIXEIRA. Índice de Desenvolvimento da Educação Básica. Disponível em: <http://ideb.inep.gov.br/>. Acesso em: 08 de fevereiro de 2018.

LEAL, E. S. Democratização do ensino superior através do PROUNI e do FIES: uma análise sobre a díade quantidade e qualidade. Repositório da Universidade Estadual da Paraíba, Campina Grande, 2016. Disponível em: <http://dspace.bc.uepb.edu.br/jspui/handle/123456789/14145> Acesso em: 19 de setembro de 2017.

MIRANDA, D. R.; ALVES, A. M. L.; CESTARO, P. M. R. Considerações sobre a qualidade na educação pré-escolar no Brasil. Revista Internacional de Educación y Aprendizaje. Volume 3, Número 2.2015 .2 Disponível em: <http://journals.epistemopolis.org/index.php/educacion/article/view/597/184>. Acesso em: 19 de setembro de 2017.

MOORE, David S. \& McCABE, George. Introduction to the practice of statistics. New York, Freeman, 2004. 
OBSERVATÓRIO DO PLANO NACIONAL DE EDUCAÇÃO. Metas do PNE. Educação Infantil. Disponível em: < http://www.observatoriodopne.org.br/metas-pne/1-educacaoinfantil>. Acesso em: 19 de fevereiro de 2018.

RAUPP, F. M.; BEUREN, I. M. Metodologia da Pesquisa Aplicada às Ciências Sociais. In: Ilse Maria Beuren. (Org.). Como Elaborar Trabalhos Monográficos em Contabilidade: Teoria e Prática. $3^{\mathrm{a}}$ ed. $8^{\mathrm{a}}$ reimpressão. São Paulo: Atlas, 2013, p. 76-97.

RIGHETTI, S. Brasil cresce em produção científica, mas índice de qualidade cai. Folha de são Paulo. Disponível em: <http://www1.folha.uol.com.br/ciencia/2013/04/1266521-brasilcresce-em-producao-cienti fica-mas-indice-de-qualidade-cai.shtml $>$. Acesso em: 19 de setembro de 2017.

RUA, M. G. Políticas Públicas. 2. ed. reimp. - Florianópolis: Departamento de Ciências da Administração / UFSC, 2012

SYLVA, K. et al. Early childhood matters: evidence from the effective pre-school and primary education project. London: Routledge, 2010.

\section{Como citar este artigo (Formato ABNT):}

RODRIGUES, Neila Carla S.; SANTOS, Josaias S. dos; LIMA FILHO, Raimundo N. Educação Infantil: Um estudo sobre a influência da oferta de vagas e a qualidade do ensino. Id on Line Rev.Mult. Psic., 2018, vol.12, n.40, p.826-842. ISSN: 1981-1179.

Recebido: $19 / 05 / 2018$

Aceito: $21 / 05 / 2018$ 